\title{
Sex differences in primary muscle afferent sensitization following ischemia and reperfusion injury
}

\author{
Jessica L. Ross ${ }^{1}$, Luis F. Queme ${ }^{1}$, Jordan E. Lamb ${ }^{1}$ Kathryn J. Green ${ }^{1}$ and Michael P. Jankowski, ${ }^{1 *}$
}

\begin{abstract}
Background: Chronic pain conditions are more prevalent in women, but most preclinical studies into mechanisms of pain generation are performed using male animals. Furthermore, whereas group III and IV nociceptive muscle afferents provoke central sensitization more effectively than their cutaneous counterparts, less is known about this critical population of muscle nociceptors. Here, we compare the physiology of individual muscle afferents in uninjured males and females. We then characterize the molecular, physiological, and behavioral effects of transient ischemia and reperfusion injury (I/R), a model we have extensively studied in males and in females.

Methods: Response properties and phenotypes to mechanical, thermal, and chemical stimulation were compared using an ex vivo muscle/nerve/dorsal root ganglia (DRG)/spinal cord recording preparation. Analyses of injury-related changes were also performed by assaying evoked and spontaneous pain-related behaviors, as well as mRNA expression of the affected muscle and DRGs. The appropriate analyses of variance and post hoc tests (with false discovery rate corrections when needed) were performed for each measure.
\end{abstract}

Results: Females have more mechanically sensitive muscle afferents and show greater mechanical and thermal responsiveness than what is found in males. With $I / R$, both sexes show fewer cells responsive to an innocuous metabolite solution (ATP, lactic acid, and protons), and lower mechanical thresholds in individual afferents; however, females also possess altered thermal responsiveness, which may be related to sex-dependent changes in gene expression within the affected DRGs. Regardless, both sexes show similar increases in I/R-induced pain-like behaviors.

Conclusions: Here, we illustrate a unique phenomenon wherein discrete, sex-dependent mechanisms of primary muscle afferent sensitization after ischemic injury to the periphery may underlie similar behavioral changes between the sexes. Furthermore, although the group III and IV muscle afferents are fully developed functionally, the differential mechanisms of sensitization manifest prior to sexual maturity. Hence, this study illustrates the pressing need for further exploration of sex differences in afferent function throughout the lifespan for use in developing appropriately targeted pain therapies.

Keywords: Ischemia, Nociception, Muscle afferents, Behavior, Molecular biology

\section{Background}

Pain is a significant problem in the USA [1]. The diffuse and subjective properties $[2,3]$, as well as the heterogeneous etiologies [4], of muscle pain complicate effective management. One particularly nefarious cause of myalgia arises from deficits in peripheral perfusion, where transient ischemia prevents adequate blood flow and oxygen

\footnotetext{
* Correspondence: michael.jankowski@cchmc.org

'Department of Anesthesia, Division of Pain Management, Cincinnati

Children's Hospital Medical Center, 3333 Burnet Ave MLC 6016, Cincinnati,

$\mathrm{OH}$ 45229, USA

2Department of Pediatrics, University of Cincinnati, Cincinnati, OH 45229, USA
}

from reaching the muscles [5-7]. This occurs in conditions such as complex regional pain syndrome (CRPS) [810], peripheral vascular disease [11, 12], sickle cell anemia [13], and fibromyalgia [14-16]. Clinical features of ischemic myalgia include decreased activity, ongoing pain, hypersensitivity, and weakness in the affected muscle tissue [17]. Correspondingly, animal models of ischemic myalgia display similar enhancements in muscle pain-like behaviors, which correlate with distinct changes in neuronal gene expression and function $[9,18-26]$ at multiple levels within the canonical pain pathway. 
Until recently, these studies have been performed primarily in male rodents, which is translationally counterintuitive as many chronic musculoskeletal pain conditions, including CRPS and fibromyalgia [5, 27], are more prevalent in women [28-30]. Furthermore, there are sexdependent effects on disease severity and patient outcomes in ischemic myalgia-associated conditions [31-34]. Because of the lack of effective therapies for ischemic myalgia, understanding how deficits in peripheral perfusion generate this type of muscle pain is crucial. To investigate these underlying mechanisms, we have established a mouse model of transient ischemia and reperfusion (I/R) injury to the forepaw muscles, but until now, have only characterized its effects in male mice [19, 35].

Recent studies examining various rodent pain models have suggested that discrete immune mechanisms contribute to sex-dependent sensitization within the spinal cord dorsal horn and brain [36-39], but examinations into sex effects on primary muscle afferents have been limited. The group III and IV afferents that innervate the muscle tissue are responsive to mechanical, thermal, and chemical stimulation, and it has been previously shown that solutions that contain all three of the common muscle "metabolites" (lactic acid, ATP, and protons) are more effective in provoking afferent chemical responses than any one or two alone [40, 41].

Using natural mechanical, thermal, and metabolite stimuli in our novel ex vivo electrophysiology preparation allows us to phenotype individual group III and IV primary muscle afferents, and thus, analyze injury-induced changes in distinct subpopulations [19, 23, 35, 42, 43]. One day after $\mathrm{I} / \mathrm{R}$ in males, the number of afferents responsive to both noxious ("high metabolite:" $\mathrm{pH}$ 6.6, high lactic acid and ATP concentrations, similar to what is produced by the muscle in ischemia $[40,44,45])$ and non-noxious ("low metabolite:" pH 7.0, low lactic acid and ATP concentrations, similar to muscle output during moderate exercise [46-49]) metabolite mixtures [40] is significantly increased. The population that is responsive only to the low metabolite solution is decreased, when compared with age-matched uninjured males $[19,35]$. I/R also decreases mechanical thresholds in group III and IV muscle afferents, corresponding with the observed behavioral phenotype [19, 35, 43]. In this study, we sought to determine how I/R injury altered the response properties of these afferents in young, pre-cycling female mice (21-35 days). Additionally, we examined the molecular and behavioral correlates of this injury condition in females compared to males.

\section{Methods}

\section{Animals}

Swiss Webster mice between 21 and 35 days of age were used in all experimental analyses. Mice were obtained from our in-house colony or direct from Charles River
(Wilmington, MA). No differences were detected between these two sources. All mice were provided ad libitum access to food and water and housed in a climate-controlled barrier facility with 12-h light/dark housing. Mice that were received from the supplier were allowed 5-7 days to habituate to our facility prior to any procedures. All experimental procedures were approved by the Cincinnati Children's Hospital Research Foundation Institutional Animal Care and Use Committee and adhered to NIH Standards of Animal Care and Use under Association for Assessment and Accreditation of Laboratory Animal Care International-approved practices. Animals were anesthetized with $3 \%$ isofluorane throughout sterile surgeries, and deeply anesthetized with $100 \mathrm{mg} / \mathrm{mL}$ ketamine and $20 \mathrm{mg} / \mathrm{mL}$ xylazine for all terminal procedures.

\section{Ischemia and reperfusion injury (I/R) and sham surgeries}

As previously described [19, 35], surgical ischemia and reperfusion injury $(I / R)$ of the right forepaw muscles were performed. Briefly, in anesthetized mice, an incision was made in the upper forelimb and the biceps were slightly retracted to expose the brachial artery proximal to the bifurcation into the ulnar and radial arteries. Connective tissue was loosened from around the vessels, and a 7-0 silk suture was tied around the brachial artery. Incisions were closed and animals were returned to their facility in clean cages. Following a 6-h occlusion period, a second surgery was performed to remove the suture from around the brachial artery. To allow adequate reperfusion time, animals were left to recover for $18 \mathrm{~h}$ before undergoing any subsequent analyses. As an additional control, sham surgeries were also performed wherein a suture was placed around the brachial artery but not tied during the initial surgery. As naïve and sham males were no different in behavior, physiology, or mRNA/protein expression in our previous reports [19, 35], and also do not differ in the physiology presented here (see Additional file 1), they have been combined as one comparison group for ease of presentation and enhancement of statistical power. However, female shams were behaviorally different from female naïves (Table 3), and as such were presented separately.

\section{Ex vivo recording}

Our novel ex vivo forepaw muscles/median and ulnar nerves/DRGs/spinal cord electrophysiology preparation was performed exactly as previously described [19, 23, $35,42]$. Mice were transcardially perfused with ice cold, oxygenated $\left(95 \% \mathrm{O}_{2} / 5 \% \quad \mathrm{CO}_{2}\right)$ artificial cerebrospinal fluid (aCSF).Then the median and ulnar nerves, forepaw, C6-T2 DRGs, and C6-T2 hemisected spinal cord were carefully dissected so that relevant connections remained intact while undergoing continuous perfusion in an ice 
cold oxygenated aCSF bath. To allow for direct access to receptive fields (RFs) in the muscle tissue, the skin was removed. The entire preparation was then transferred to a two-chambered recording dish. Suction electrodes were placed on the median and ulnar nerves and the aCSF was slowly warmed to $32{ }^{\circ} \mathrm{C}$. Electrically responsive cells were located with an orthograde search stimulus from the suction electrode, and then the RF was found in the muscle using a concentric electrode. RFs were then stimulated with an increasing series of von Frey filaments $(0.07$ to $10 \mathrm{~g})$, cold $\left(0{ }^{\circ} \mathrm{C}\right)$ and hot $\left(53{ }^{\circ} \mathrm{C}\right)$ physiological saline, and finally, oxygenated "low" (15 mM lactate, $1 \mathrm{mM}$ ATP, pH 7.0) and "high" (50 mM lactate, $5 \mathrm{mM}$ ATP, $\mathrm{pH}$ 6.6) metabolite mixtures to assess mechano-, thermo-, and chemo- sensitivity, respectively. ATP was added to the metabolite solutions immediately before application to prevent degradation. After chemical stimulation, mechanical and thermal responsiveness was re-assessed.

In this study, 143 cells were characterized using ex vivo recording: 50 cells from 12 individual naïve females, 47 cells from 13 I/R females, and 46 cells from 12 naïve/ sham males. Group III and IV afferents were not significantly different in our samples and were combined for analysis. Data was captured and stored for offline analysis using Spike2.5 (CED). With analysis of every cell, response phenotypes and mechanical thresholds (if present) were confirmed and peak instantaneous frequencies (IF), used to approximate the maximum rate of action potential generation [50], were obtained for each observed response type. Unlike previous observations in males [19, 35], certain parameters in female muscle afferents were found to differ before and after the application of the metabolite solutions used to assess chemosensitivity. Hence, we performed additional analysis to determine whether sex- or injury-dependent changes in afferent sensitivity were ongoing (cumulative peak IF or minimum threshold across recording for each individual cell) or specific to pre- or post-metabolite stimulation. Similar to previous reports, no differences in response properties were observed between cells obtained at the beginning of the recording session compared to the end $[19,23,35,42]$.

\section{RNA isolation, reverse transcription, and real-time PCR}

Quantitative real-time polymerase chain reaction (PCR) was performed as described previously $[19,51]$. Following transcardial perfusion with a 1:1 solution of $0.9 \%$ $\mathrm{NaCl}$ : RNA-later (Ambion), the ipsilateral forepaw muscles and $\mathrm{C} 7 / \mathrm{C} 8 / \mathrm{T} 1$ DRGs were excised from age- and sex-matched naïve or 1-day I/R mice. Qiagen RNeasy kits (Qiagen, Valencia, CA) were used to isolate RNA from both regions, either using the standard protocol (DRG) or using the protocol for fibrous tissues (muscle).
RNA concentrations were measured on a Nanodrop spectrometer (Thermo) and $500 \mu \mathrm{g}$ of total RNA from each sample was treated with DNase I, then Superscript II reverse transcriptase (both Invitrogen, Carlsbad, CA). Each real-time PCR reaction was executed in duplicate using $20 \mu \mathrm{g}$ cDNA with SYBR Green reagents and analyzed on a Step-One real-time PCR machine (Applied Biosystems, Foster City, CA).

Forward and reverse primer sequences for glyceraldehyde 3-phosphate dehydrogenase (GAPDH), GFR $\alpha 3$, ASIC1, ASIC3, and TRPV1 were obtained from Elitt and colleagues [52]. We have previously reported primer sequences used for NGF, NT-3, artemin, P2X3, and P2Y1 [53], for IL-1r1, IL-1 $\beta$, P2X5, and GDNF [19], and for IL-6 [54]. For the remaining genes investigated in this study, the forward and reverse primer sequences are as follows: interleukin-6 receptor (IL6R): forward, $5^{\prime}$-CCA CCG TTA CCC TGA TTT G-3'; reverse, 5' -GTG TGT TTC CTG TGG TAG TC-3'; monocyte chemoattractant protein 1 (MCP-1): forward, 5'-CAC CTG CTG CTA CTC ATT C-3'; reverse, 5'-CTA CAG CTT CTT TGG GAC AC-3'; P2X4: forward, 5'-GGA GGC ATC ATG GGT ATC CA-3'; reverse, 5'-GTG GGA GGC AGC TCT GTC A-3'; tumor necrosis factor $\alpha$ (TNF $\alpha)$ : forward, 5'-CCT ATG TCT CAG CCT CTT CT-3'; reverse, 5'-GGG AAC TTC TCA TCC CTT TG-3'; TNFo receptor (TNF $\alpha$ R): forward, 5'-TCG GAA AGA AAT GTC CCA GGT GGA-3'; reverse, 5'-TGG AAC TGG TTC TCC TTA CAG CCA-3'; TRPM8: forward, 5'TCT CAC CAA TGA AGT CCT CAC AGA-3'; reverse, 5'-TTC CAC ATC CAA GTC CTC CCT G-3'.

GAPDH was used as an internal control in both tissues, and the mean target $\mathrm{Ct}$ value of each sample was normalized to the mean GAPDH Ct value for that sample $(\Delta \mathrm{Ct})$. Gene expression changes following injury were detected by calculating $\Delta \Delta \mathrm{Ct}$, whereby the mean target $\Delta \mathrm{Ct}$ from naïve females was subtracted from the mean target $\Delta \mathrm{Ct}$ from $\mathrm{I} / \mathrm{R}$ females. The fold-change and error as difference in means for each target gene were then calculated as $2^{\Delta \Delta \mathrm{Ct}}$ (Applied Biosystems). For clarity of presentation, values were converted to percent change where two-fold $=100 \%$.

\section{Protein isolation and western blotting}

Protein isolation and Western blot were performed according to our previously detailed procedures $[23,35,51$, 54]. At 1 day, the right forepaw muscles of three female mice from each condition were excised following transcardial perfusion with $0.9 \% \mathrm{NaCl}$. Muscles were then homogenized in lysis buffer containing 1\% SDS, $10 \mathrm{mM}$ Tris-HCl ( $\mathrm{pH}$ 7.4), and protease inhibitors $(1 \mu \mathrm{g} / \mathrm{ml}$ pepstatin, $1 \mu \mathrm{g} / \mathrm{ml}$ leupeptin, $1 \mu \mathrm{g} / \mathrm{ml}$ aprotinin, $1 \mathrm{mM}$ sodium orthovanadate and $100 \mu \mathrm{g} / \mathrm{ml}$ phenylmethylsulfonyl fluoride; Sigma-Aldrich). Then, a denaturing buffer 
containing $\beta$-mercaptoethanol and SDS was added to $30 \mu \mathrm{g}$ of each sample. After boiling for $10 \mathrm{~min}$, the sample solutions were separated on a $12 \%$ SDS-PAGE gel. Proteins were transferred overnight at $4{ }^{\circ} \mathrm{C}$ to a polyvinylidene difluoride (PVDF) membrane (Millipore), which was then blocked in 1:1 LiCor Odyssey blocking buffer in 0.1 M PB, and processed overnight at $4{ }^{\circ} \mathrm{C}$ with primary antibodies for GAPDH (chicken $\alpha$-GAPDH, 1:2000, ProSci) and IL1 $\beta$ (goat $\alpha$-IL1 $\beta, 1: 2000, R \& D$ Systems). Infrared-dye conjugated secondary antibodies [donkey anti-chicken $680 \mathrm{~nm}$ $(1: 20,000)$ and donkey anti-goat $800 \mathrm{~nm}(1: 15,000)]$ were then applied for detection on a LiCor Odyssey Imaging System using Image Studio v3.1 (LiCor) with consistent detection settings between runs. Image $(\mathrm{NIH})$ was used for densitometry to quantify protein expression of immunoreactive bands relative to GAPDH, and optical density represented as fold-change (mean \pm SEM).

\section{Behavioral analyses}

As previously described [19, 23, 35], behavioral analyses of evoked and spontaneous pain-related behaviors were performed by a blinded observer during morning light hours at baseline (BL; immediately before $\mathrm{I} / \mathrm{R}$ ) and days 1,3 , and 5 after I/R (D1, D3, and D5, respectively). Mice were first habituated to a raised acrylic glass chamber with a steel mesh bottom for $30 \mathrm{~min}$. For assessment of ongoing/ spontaneous pain, guarding behaviors [55] were assessed for each forelimb every $5 \mathrm{~min}$ for $1 \mathrm{~h}$. Guarding scores of $0-2$ were thus assigned 12 times based on the following criteria: $0=$ full weight-bearing on paw, $1=$ weight not firmly distributed on paw, 2 = paw held completely above (not touching) mesh, and averaged for each mouse for analysis of each behavior time point. Evoked mechanical hypersensitivity was quantified using a von Frey paw withdrawal paradigm. For this, the plantar surface of the forepaws was stimulated with an increasing series of calibrated von Frey filaments (0.07-6 g), and paw withdrawal thresholds for each mouse were averaged from three rounds with 5 min between rounds on each behavioral day. Finally, muscle function was tested with a grip strength meter (BioSeb) in three rounds of three trials each with $5 \mathrm{~min}$ in home cages between rounds. Mice were held by the tail over the mesh grid of the meter, and once the forepaws, but neither hindpaw, were both firmly grasping the grid, mice were pulled along the axis of the force sensor until they were unable to retain their grip. The nine grip strength measurements (in grams) were then averaged for each mouse on each behavioral day for analysis.

\section{Statistical analyses}

Comparisons of response properties from ex vivo recordings that adhered to a normal distribution were performed with condition $\mathrm{x}$ time two-way analysis of variance (ANOVA) with Holm-Sidak, where condition represents either injury or sex, and time refers to pre- or post-metabolite stimulation as this was found to alter response properties in female preparations. Comparisons of non-normal ex vivo mechanical threshold data were analyzed with Kruskal-Wallis one-way ANOVA on ranks followed by Dunn's post-test, and analysis of afferent phenotype frequency was performed with $\chi^{2}$ or Fisher's exact test. All two-way (injury $\mathrm{x}$ sex) comparisons of mRNA expression were performed using two-way ANOVAs with Holm-Sidak post hoc analyses on individual $\Delta \mathrm{Ct}$ values for each gene. To validate gene expression results, within sex comparisons for each gene were made using the Mann-Whitney Rank-Sum test, and all analyses also underwent the false discovery rate procedure to correct for multiple comparisons. Western blot data was examined with one-way ANOVA and Tukey's test, and behavioral data was analyzed using two-way repeated measures (RM) ANOVA (condition $x$ time) with Holm-Sidak post hoc. Because pain-related behaviors in females who underwent a sham surgical procedure were often found to not differ from either the naïve or I/R conditions, behavioral data are presented here both with (Table 3) and without (Fig. 5) an age-matched sham comparison group.

\section{Results}

Basal sex differences in mechanical sensitivity and heat responses of primary group III and IV muscle afferents

To provide a stronger foundation for investigating postinjury mechanisms of sensitization in individual group III and IV muscle afferents in females, afferent response properties and phenotypes from naïve females and naïve/sham males were first assessed using our ex vivo muscle/nerve/DRG/spinal cord preparation (Fig. 1). The population distribution of response phenotypes was similar between uninjured males and females, and there were no differences in numbers of cells responsive to cold, hot, or metabolite stimulation. However, female muscle afferents were significantly more likely to respond to mechanical stimulation (males: 12/46, females: 25/50, $p=0.021$, Fisher's Exact; Fig. 1a).

As metabolite stimulation may affect responses to other stimuli, we also assessed the frequency of responders to our various stimuli both before and after chemical stimulation. We found that females displayed more mechanically sensitive afferents at both intervals (Fig. 1b; pre-metabolite: males: $7 / 46$, females: 21/49, $p=0.004$; post-metabolite: males: $6 / 35$, females: $15 / 25, p<0.001$; both Fisher's Exact). There was no difference in number of metabolite responsive cells (as low/high/both responders/total tested, males: $8 / 8 / 2 / 36$, females: $7 / 7 / 3 / 32$ ); however, peak instantaneous frequency to mechanical stimulation was increased in females following metabolite 

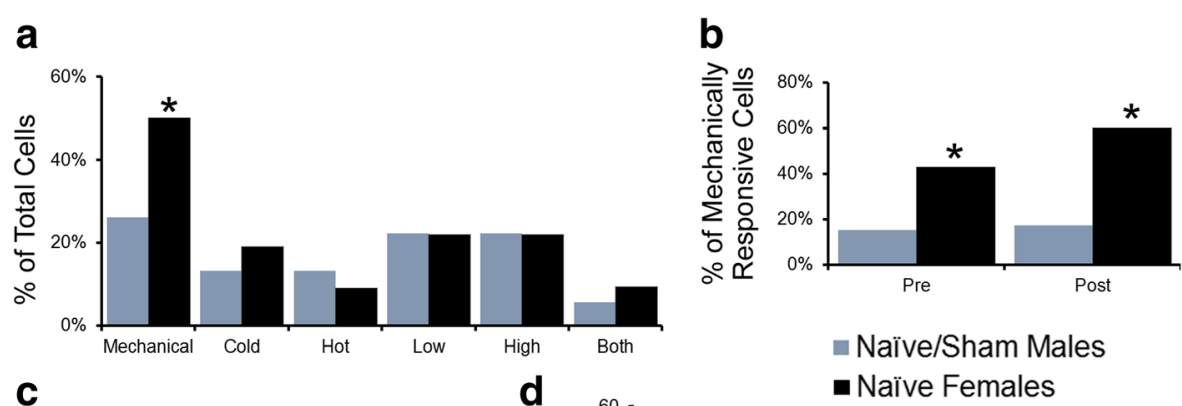

naïve/Sham Males

- Naïve Females
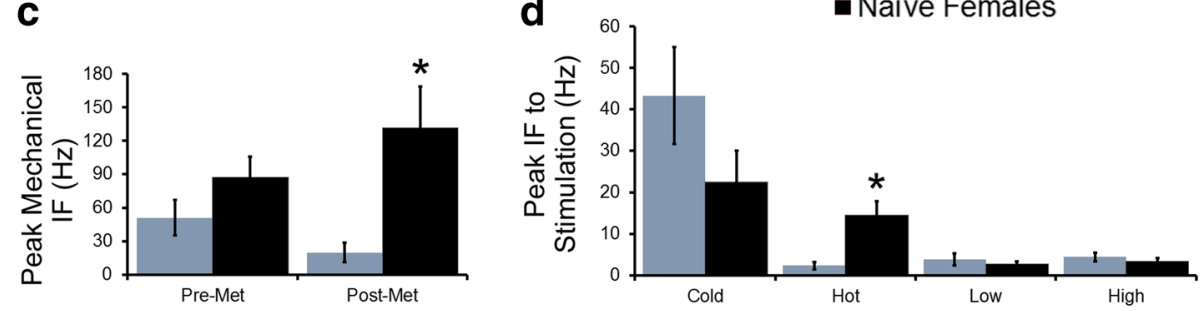

e

$$
\begin{gathered}
\text { Male } \\
\text { Mechanical } \\
\text { Responses } \\
\text { (2g Filament) }
\end{gathered}
$$

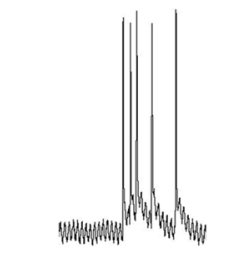

Pre-Metabolite

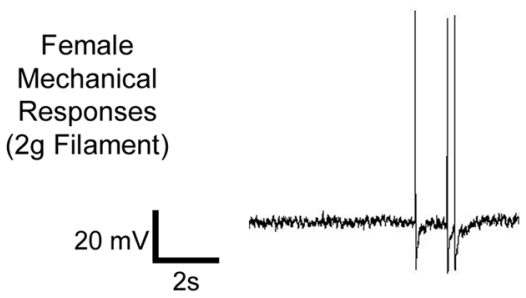

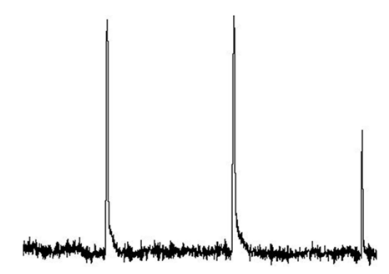

Post-Metabolite

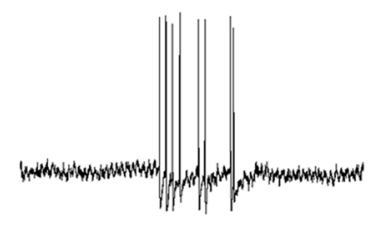

Fig. 1 Response properties and phenotypes of individual muscle afferents in age-matched uninjured males and females. a Phenotype distribution of male $(n=46)$ and female afferents $(n=50)$ did not differ for most modalities; however, female muscle afferents were more likely to be mechanically sensitive. $\mathbf{b}$ Sex differences in the numbers of mechanoreceptors was observed both prior to and following the application of metabolite solutions, but firing of these afferents to mechanical stimulation only showed a significant increase in firing after metabolite application c. With the exception of post-metabolite mechanical responses and peak heat responses, firing to other stimulus modalities did not differ between males and females (d). Representative traces of pre- and post-metabolite mechanical responses to stimulation with a $2 \mathrm{~g}$ von Frey filament (e). Phenotype data is represented as the percentage of cells responsive to a given stimulus over the total tested in a condition, and the corresponding raw frequency data was analyzed with Fisher's Exact test. Peak IFs are represented by the condition average \pm error of the difference in means. ${ }^{*} p<.05$ vs. other condition

stimulation (Fig. 1c, e; $p=0.034$, Holm-Sidak post hoc analyses following two way ANOVA with main effect of $\operatorname{sex} p=0.027$ ), suggesting that the application of metabolite solutions alters firing in mechanically sensitive cells in a sex-dependent manner.

Firing to the low and high metabolite solutions, as well as to cold stimulation was no different between males and females (all $p>0.13$, one-way ANOVA; Fig. 1d), and no sex differences were detected in mechanical thresholds of individual afferents (pre-met: males: $4.72 \pm$ 2.17 g, females: $3.10 \pm 0.82$ g; post-met: males: $5.40 \pm$ 2.66 g, females: $3.63 \pm 0.76$ g, all $p>0.05$, Kruskal-Wallis ANOVA on Ranks). Interestingly, despite a similarly small proportion of heat-responsive afferents in both sexes (males: 6/45, females: 4/44, $p=0.742$, Fisher's Exact; Fig. 1a), the heat-sensitive cells of females were significantly more responsive to heat stimulation (Fig. 1d; males: 2.38 $\pm 0.91 \mathrm{~Hz}$, females: $14.47 \pm 3.47 \mathrm{~Hz}, p=0.004$, one-way ANOVA with Holm-Sidak).

We then compared baseline behaviors in male $(n=8)$ and female $(n=15)$ mice in order to determine if alterations in afferents corresponded to any distinctions in sensory-related behaviors. As expected, neither male $(0.1 \pm 0.04)$ nor female $(0.0 \pm 0.02)$ mice displayed any paw guarding behaviors if uninjured $(p>0.05)$. Additionally, both male $(3.1 \pm 0.25 \mathrm{~g})$ and female $(2.8 \pm 0.29 \mathrm{~g})$ 
mice show similar mechanical withdrawal thresholds (Fig. 2a; $p>0.05)$. However, female $(88.8 \pm 5.2 \mathrm{~g})$ mice display significantly reduced grip strength compared to age-matched male $(113.0 \pm 1.9 \mathrm{~g})$ mice (Fig. 2b; $p<0.003$, one-way ANOVA with Holm-Sidak).

\section{Transient ischemia and reperfusion injury (I/R) alters group III and IV muscle afferent responsiveness in females}

Our ex vivo muscle preparation was also used to characterize afferent response properties and phenotypes 1d following transient ischemia and reperfusion injury (I/R) in female mice, which we have thoroughly examined in males $[19,35]$. The prevalence of mechanically and thermally sensitive fibers was not affected by I/R; but the number of cells responsive to low metabolite solutions was significantly decreased following this injury (Fig. 3a; naïve: 7/32, I/R: 1/33; $p=0.021$, Fisher's Exact). Additionally, I/R females showed decreased thresholds to mechanical stimulation, particularly following metabolite exposure [Fig. 3b, f; Pre-met Threshold (median $\left\{\mathrm{Q}_{1}: \mathrm{Q}_{3}\right\}$ ): naïve: $1.0\{0.6: 6\} \mathrm{g}, \mathrm{I} / \mathrm{R}: 0.6\{0.4: 1.5\} \mathrm{g}, p=0.064$; post-met threshold: naïve: $4.0\{1: 6\}$ g, I/R: $0.28\{0.16: 0.55\}$ g, $p=0.004$; minimum threshold: naïve: $1.5\{1: 6\} \mathrm{g}, \mathrm{I} / \mathrm{R}$ : $0.5\{0.22: 2\}$ g, $p=0.045$; all Kruskal-Wallis ANOVA on Ranks], but firing to mechanical stimulation was no different compared to naïve females (Fig. 3c, f).

$\mathrm{I} / \mathrm{R}$ also altered the responses of individual muscle afferents to thermal stimulation. When compared with age-matched naïve cold responders, firing to cold stimulation was increased by $I / R$, and was particularly enhanced prior to metabolite exposure (Fig. 3d, f; Pre-met Peak IF: naïve: $17.5 \pm 9.1 \mathrm{~Hz}, \mathrm{I} / \mathrm{R}: 63.3 \pm 20.8 \mathrm{~Hz}$; postmet peak IF: naïve: $16.9 \pm 8.9 \mathrm{~Hz}, \mathrm{I} / \mathrm{R}: 50.4 \pm 16.6 \mathrm{~Hz}$; cumulative peak IF: naïve: $25.2 \pm 8.0 \mathrm{~Hz}$, I/R: $62.4 \pm$ $18.5 \mathrm{~Hz}$; two-way ANOVA condition $\mathrm{x}$ time with main effect of condition $p=0.021$ and Holm-Sidak post hoc condition within pre-met $p=0.048$ ). Heat responses showed a similar pattern; however, the small number of cells responsive to heat (naïve: 4/44, I/R: 7/40) limited statistical power, thus $I / R$ effects on firing of heat- sensitive muscle afferents in females are inconclusive (Fig. 3e, f; Pre-met Peak IF: naïve: $9.9 \pm 5.2 \mathrm{~Hz}, \mathrm{I} / \mathrm{R}: 57.2$ $\pm 29.3 \mathrm{~Hz}$; Post-met Peak IF: naïve: $16.6 \pm 3.4 \mathrm{~Hz}, \mathrm{I} / \mathrm{R}$ : $13.8 \pm 6.2 \mathrm{~Hz}$; Cumulative Peak IF: naïve: $14.5 \pm 3.5 \mathrm{~Hz}$, I/R: $54.4 \pm 24.6 \mathrm{~Hz}$ ). Unlike previous phenotype differences in I/R males [19], the proportions of cells responsive to one, two, or three or more modalities did not differ between naïve and I/R females (data not shown).

\section{I/R induces sex-dependent Upregulation of sensory} receptors despite similar increase in muscle IL1 $\beta$

We have previously documented [19, 23, 35] that ischemic injury evokes dynamic upregulation of sensoryrelated receptors within the affected DRGs in males, which correlated with increased muscle afferent sensitivity and in vivo pain-related behaviors. I/R injury, specifically, resulted in enhanced IL1 $\beta$ within the muscle that acted at its upregulated receptor, IL1r1, within the DRGs to stimulate de novo ASIC3 expression [19, 35]. Here, we sought to investigate whether altered IL1 $\beta /$ IL1r1 signaling or similar mechanisms following I/R correspond with the observed injury-related afferent physiology changes in females. To that end, mRNA expression levels of genes related to male I/R-evoked hypersensitivity were assessed in naive and $I / R$ mice of both sexes using qPCR. Validating our past results [19, 35], males showed I/R evoked increases in acid-sensing ion channels (ASICs) 1 and 3, as well as the interleukin-1 receptor (IL1r1), and the purinergic receptors P2X3 and P2X5 within the affected DRGs; however, of these receptors, only IL1r1 and P2X3 were upregulated in females (Table 1). Additionally, whereas males show no I/R-related increase in the transient receptor potential family members that participate in cold and heat sensation, TRPM8 and TRPV1, respectively, this same injury evoked a substantial increase in both TRPM8 and TRPV1 in females.

To further characterize DRG gene expression in females, we tested an additional panel of sensory-related receptors. Like previous observations in males [19], we found that $I / R$ did not change the expression of the
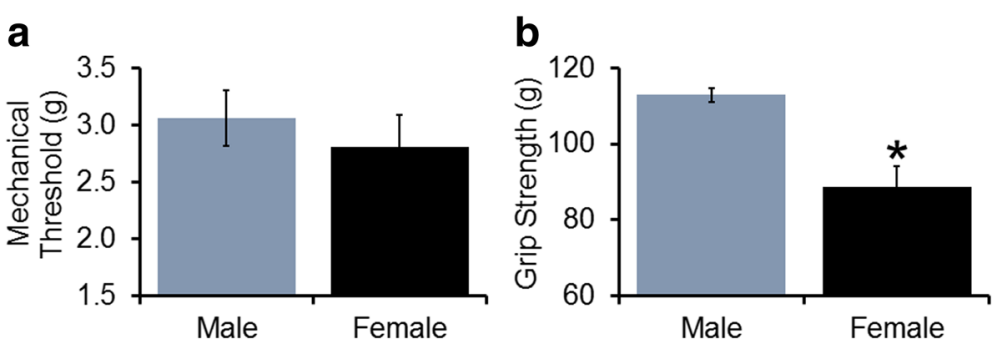

Fig. 2 Comparison of baseline behaviors in male and female mice. a Male and female mice display similar mechanical withdrawal thresholds upon stimulation of the forepaws. $\mathbf{b}$ Female mice have significantly reduced grip strength compared to age-matched male mice. ${ }^{*} p<0.003$ vs males, one-way ANOVA with Holm-Sidak 

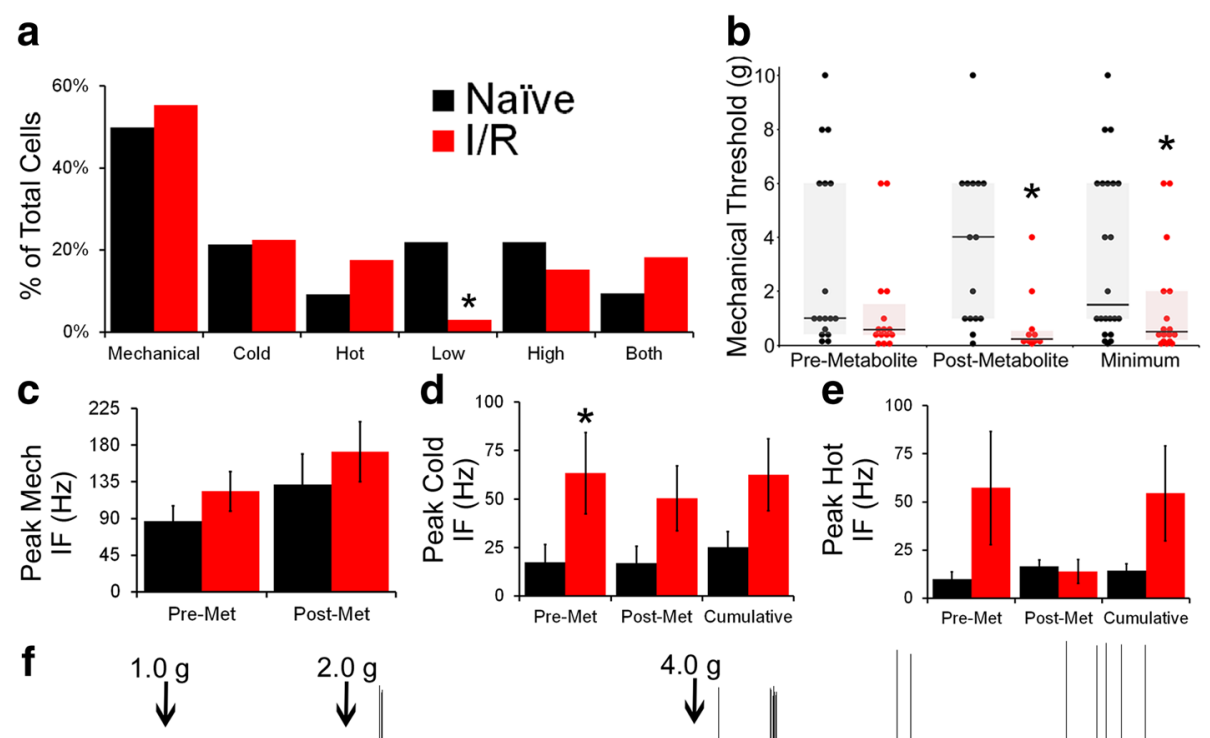

e
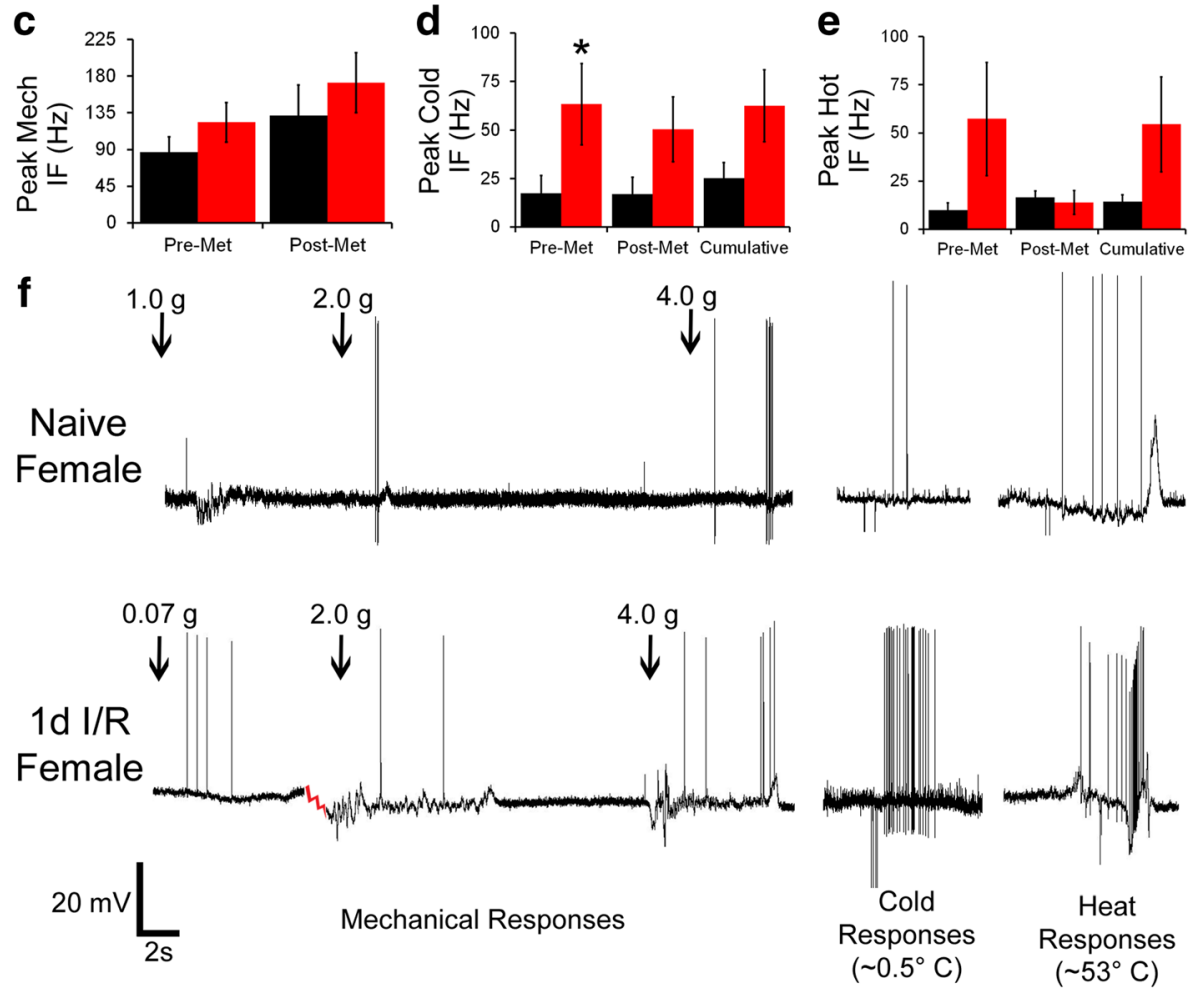

Fig. 3 Alterations in response properties and phenotypes of female muscle afferents following I/R. a Although minor augmentations in cells responsive to heat or both metabolite solutions were observed, the only significant I/R-evoked difference in afferent phenotype distribution in females was a decreased population of cells that were only responsive to the low metabolite solution. $\mathbf{b}$ I/R also was found to decrease the mechanical threshold of individual mechanoreceptors, without altering mean peak instantaneous frequencies (IF) to mechanical stimulation (c). Increased firing to cold stimulation was observed following I/R in females (d), and a similar, but nonsignificant, trend toward I/R-evoked increased heat IF was also seen (e). Representative traces from naïve and Id I/R ex vivo preparations showing responses to mechanical and thermal stimulation ( $\mathbf{f}$. Phenotype data is represented as the percentage of cells responsive to a given stimulus over the total tested in a condition. Mechanical thresholds of individual neurons are plotted with median and interquartile range demarcated. Peak IF is represented by the condition average \pm error of the difference in means. ${ }^{*} p<.05$ between conditions

artemin-responsive growth factor receptor, GDNF family receptor $\alpha 3$ (GFR $\alpha 3$ ) or the ADP-receptor P2Y1, but led to increased P2X4 mRNA expression (Table 2). Furthermore, naïve and $\mathrm{I} / \mathrm{R}$ females did not differ in expression of receptors for the cytokines tumor necrosis factor $\alpha$ (TNF $\alpha$ R) and interleukin-6 (IL6r).

Additionally, mRNA expression of neurotrophic factors, growth factors, and cytokines within the muscle tissue was compared between naïve and I/R females (Table 2); however, none of the tested factors were found to be significantly enhanced at the mRNA level. Because both sexes showed upregulation of IL1r1 mRNA following I/
$R$, we elected to further examine muscle IL1 $\beta$ via Western blot (Fig. 4), finding that IL1 $\beta$ protein is indeed elevated in females $1 \mathrm{~d}$ following $\mathrm{I} / \mathrm{R}$ as compared with naïves (optical density in arbitrary units; naïve: $0.854 \pm$ 0.05 , I/R: $1.464 \pm 0.20 ; p=0.045$, one-way ANOVA with Tukey's post hoc).

\section{I/R increases pain-related behaviors}

In male mice, $\mathrm{I} / \mathrm{R}$ was previously observed to alter three pain-related behaviors that together allow us to observe discrete facets of muscle pain in our animal injury model when also assessing afferent sensitization $[19,35]$. Here, 
Table 1 Percent changes in mRNA from C7/C8/T1 DRGs in male and female mice

\begin{tabular}{|c|c|c|c|c|c|c|}
\hline \multirow[t]{2}{*}{ Gene } & \multirow{2}{*}{$\begin{array}{l}\text { Naïve female expression } \\
\text { (Relative to naïve males) }\end{array}$} & \multicolumn{2}{|c|}{ I/R-induced upregulation } & \multicolumn{3}{|c|}{ Two-way comparisons } \\
\hline & & Male & Female & Injury & Sex & Interaction \\
\hline ASIC1 & $15.3 \pm 17 \%$ & $77.1 \pm 13 \%$ * & $34.8 \pm 17 \%$ & $<0.001$ & 0.955 & 0.193 \\
\hline ASIC3 & $-9.7 \pm 12 \%$ & $85.0 \pm 9 \% *$ & $10.6 \pm 11 \%$ & $<0.001$ & $<0.001$ & 0.002 \\
\hline IL1r1 & $-10.1 \pm 17 \%$ & $74.0 \pm 10 \% *$ & $95.0 \pm 23 \% *$ & $<0.001$ & 0.698 & 0.659 \\
\hline $\mathrm{P} 2 \times 3$ & $-59.7 \pm 29 \% *$ & $75.8 \pm 23 \% *$ & $181.9 \pm 21 \%{ }^{*}$ & $<0.001$ & $<0.001$ & 0.112 \\
\hline$P 2 \times 5$ & $-33.7 \pm 18 \%$ & $50.2 \pm 8 \% *$ & $63.2 \pm 22 \% *$ & $<0.001$ & 0.004 & 0.740 \\
\hline TRPM8 & $-46.4 \pm 20 \% *$ & $17.8 \pm 19 \%$ & $93.4 \pm 24 \% *$ & 0.005 & 0.01 & 0.085 \\
\hline TRPV1 & $-40.1 \pm 14 \% *$ & $42.3 \pm 23 \%$ & $133.7 \pm 17 \%$ * & $<0.001$ & 0.078 & 0.098 \\
\hline
\end{tabular}

Values indicate percentage change in mRNA expression of naïve females relative to naïve males and 1d I/R animals of both sexes relative to sex- and age-matched naïve controls \pm error of the difference in means $(n=4-11$ per condition). Final $* P<.05$ obtained via false discovery rate correction following two-way ANOVA on raw sample $\Delta \mathrm{Cts}$

these behaviors were also assessed in females at baseline (BL) and 1, 3, and 5 days following I/R injury (D1, D3, D5, respectively). To assay spontaneous or ongoing pain, we observed forelimb guarding over the course of $1 \mathrm{~h}$ (Fig. 5a). Interestingly, guarding scores of both naïve and I/R mice were significantly increased at D1 compared with their respective BLs (naïve: BL: $0.03 \pm 0.02, \mathrm{D} 1$ : $0.29 \pm 0.09, p=0.009 ; \mathrm{I} / \mathrm{R}: \mathrm{BL}: 0.04 \pm 0.02 ; \mathrm{D} 1: 0.62 \pm$ $0.07, p<0.001)$. Regardless, I/R female guarding scores were significantly higher than age-matched naïves at D1 and D3, and not at BL or D5 (D3 I/R: $0.32 \pm 0.12$; two-way RM ANOVA condition $\mathrm{x}$ time with HolmSidak, interaction effect $p=0.008)$. Naïve guarding scores on D3 and D5 did not differ from BL values (Naive D3: $0.04 \pm 0.02$, D5: $0.01 \pm 0.01$ ), and the I/Revoked increase in guarding was restored to $\mathrm{BL} /$ naïve levels at D5 (I/R: $0.03 \pm 0.01)$.

Mechanical withdrawal thresholds were then tested by stimulating the forepaws with an increasing series of von Frey filaments (0.07 g-6 g; Fig. 5b). Naïve and I/R females did not differ in BL mechanical threshold (naïve: $2.53 \pm 0.37 \mathrm{~g} ; \mathrm{I} / \mathrm{R}: 2.80 \pm 0.29 \mathrm{~g}, p=0.515$ ), but only I/R

Table 2 l/R-induced changes in gene expression in female forepaw muscles and C7/C8/T1 DRGs relative to naïves

\begin{tabular}{llll}
\hline Gene & DRG expression & Gene & Muscle expression \\
\hline GFRa3 & $4.5 \pm 24 \%$ & Artemin & $-38.1 \pm 43 \%$ \\
IL6R & $-20.8 \pm 46 \%$ & GDNF & $42.5 \pm 26 \%$ \\
P2X4 & $108.3 \pm 15 \% *$ & IL-1 $\beta$ & $-7.6 \pm 62 \%$ \\
P2Y1 & $-6.3 \pm 22 \%$ & IL-6 & $-44.3 \pm 53 \%$ \\
TNFaR & $-20.7 \pm 45 \%$ & MCP-1 & $53.4 \pm 75 \%$ \\
& & NGF & $-14.6 \pm 15 \%$ \\
& & NT-3 & $-10.5 \pm 25 \%$ \\
& & TNFa & $-2.5 \pm 29 \%$ \\
\hline
\end{tabular}

Values indicate percentage change relative to sex- and age-matched naïve controls \pm error of the difference in means ( $n=6-11$ per condition). ${ }^{*} P<.05$ vs. naïve obtained via Mann-Whitney Rank-Sum tests for each gene on raw sample $\Delta$ Cts, followed by the false discovery rate multiple comparisons correction within each tissue type mice experienced a threshold decrease at D1 (naïve: $1.66 \pm .22 \mathrm{~g}, p=0.094$ vs. BL; I/R: $0.90 \pm 0.13 \mathrm{~g}, p<0.001$ vs. $\mathrm{BL})$, the sole time point wherein $\mathrm{I} / \mathrm{R}$ thresholds were significantly lower than naïves (D1 $p<0.001$, D3/D5 naïve vs. $\mathrm{I} / \mathrm{R} p \geq 0.18)$. For $\mathrm{I} / \mathrm{R}$ mice, thresholds were decreased from $\mathrm{BL}$ on all testing days (D3: $0.97 \pm 0.18 \mathrm{~g}$, $p<0.001$; D5: $1.44 \pm 0.15 \mathrm{~g}, p=0.007$ ), whereas naïve females experienced a significant decrease from their respective $\mathrm{BL}$ values at D5 (D3: $1.52 \pm 0.18, p=0.25$; D5: $1.37 \pm 0.13, p=0.037)$.

Finally, grip strength was measured as a means of testing forepaw muscle function (Fig. 5c). D1 grip strength was found to decrease from $\mathrm{BL}$ in $\mathrm{I} / \mathrm{R}$ mice (BL: $88.4 \pm$ $5.2 \mathrm{~g}, \mathrm{D} 1: 78.5 \pm 5.8 \mathrm{~g}, p=0.006$ ); however, changes in naïve females were not detected until D5, when grip strength was significantly enhanced over naïve BL and D1 assessments (BL: $78.8 \pm 5.1 \mathrm{~g}$, D1: $79.8 \pm 5.2 \mathrm{~g}$, D5: $96.7 \pm$ 4.9 g, $p=0.006$ vs. BL, $p=0.021$ vs. D1). I/R evoked grip strength decrement differed from naïves at D1 (naïve: $0.68 \pm 2.2 \%, \mathrm{I} / \mathrm{R}:-6.82 \pm 2.0 \%, p=0.008$ ) and $\mathrm{D} 5$ (naïve: $8.03 \pm 2.0 \%, \mathrm{I} / \mathrm{R}: 0.30 \pm 2.3 \%, p=0.026)$, but not at D3 (naïve: $1.90 \pm 1.6 \%, \mathrm{I} / \mathrm{R}:-3.18 \pm 2.1 \%, p=0.242$ ).

These three behaviors were also assessed at the same time points in age-matched females that had undergone a sham surgical procedure, and unlike in male sham animals [19, 35], there were behavioral differences from naïves; hence this data has been separately analyzed in Table 3 to prevent statistical dilution during analysis of I/R-induced ischemic myalgia-like behaviors in females. Although sham females showed similar outcomes on BL and D1 guarding to naïve females, similar to $\mathrm{I} / \mathrm{R}$ females, sham guarding scores remained elevated relative to $\mathrm{BL}$ measurements on D3. Furthermore, they did not differ from $\mathrm{I} / \mathrm{R}$ females in measurements of grip strength. In assessment of mechanical withdrawal thresholds, sham females showed significantly lower BL thresholds than both the naïve and I/R groups, but they were no different from either group at any other time point. 


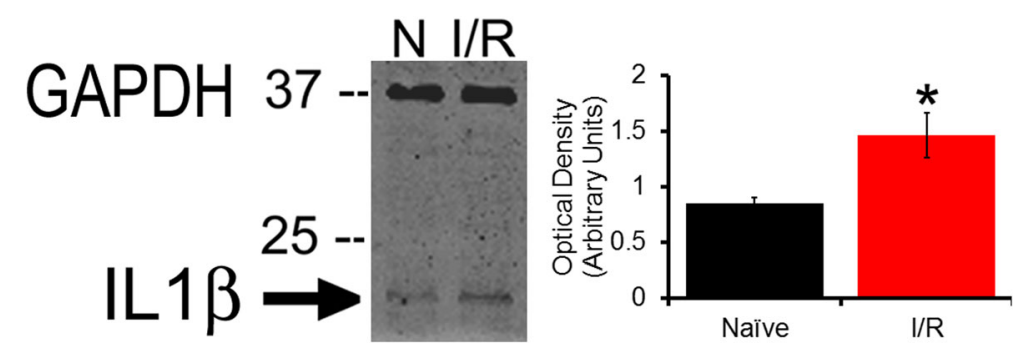

Fig. 4 Increased muscle IL1 $\beta$ following I/R in females. Muscles were excised and protein isolated from age-matched naïve and 1 day I/R females. Shown are a representative blot and quantification data of IL1 $\beta$ normalized to GAPDH. Optical density is represented by the condition average \pm error of the difference in means where $n=3 .^{*} p<.05$ between conditions as assessed by one-way ANOVA with Tukey's test

To directly compare males and females with $\mathrm{I} / \mathrm{R}$ and confirm previous reports [19, 23, 35], we also assessed BL and D1 pain-related behaviors in both sexes. Both male $(0.9 \pm 0.12)$ and female $(0.6 \pm 0.07)$ mice with $\mathrm{I} / \mathrm{R}$ showed increased ipsilateral paw guarding $(p<0.01)$ compared to individual BL measurements; however, males displayed slightly but statistically increased D1 scores compared to females (Fig. 5 d; $p<0.05$ ). I/R injury was found to reduce mechanical withdrawal thresholds in males $(0.6 \pm 0.1 \mathrm{~g})$ and females $((0.9 \pm 0.1 \mathrm{~g})$ at D1 $(p<0.01)$ but this was not found to be different between sexes (Fig. 5e; $p>0.05$ ). Finally, although we previously found that males and females display significant differences in BL grip strength (see Fig. 2b), both male $(-10.9 \pm$ $1.05 \%)$ and female $(-6.8 \pm 1.97 \%)$ mice display a similar grip strength decrement at D1 following I/R relative to BL measurements (Fig. 5f; $p<0.05$ ).

\section{Discussion}

Females and males show differing pain tolerance and prevalence of pain conditions in clinical reports [29, 5658]. Sex-dependent pain mechanisms have also been described in rodent models [36, 37, 39, 59]. However, the physiological effects of sex-dependent primary afferent sensitization have yet to be understood, particularly in regard to muscle nociceptors. In this study, we first compared the response properties and phenotypes of individual group III and IV muscle afferents in agematched uninjured males and females, which yielded basal sex differences (Fig. 1). Notably, the population of

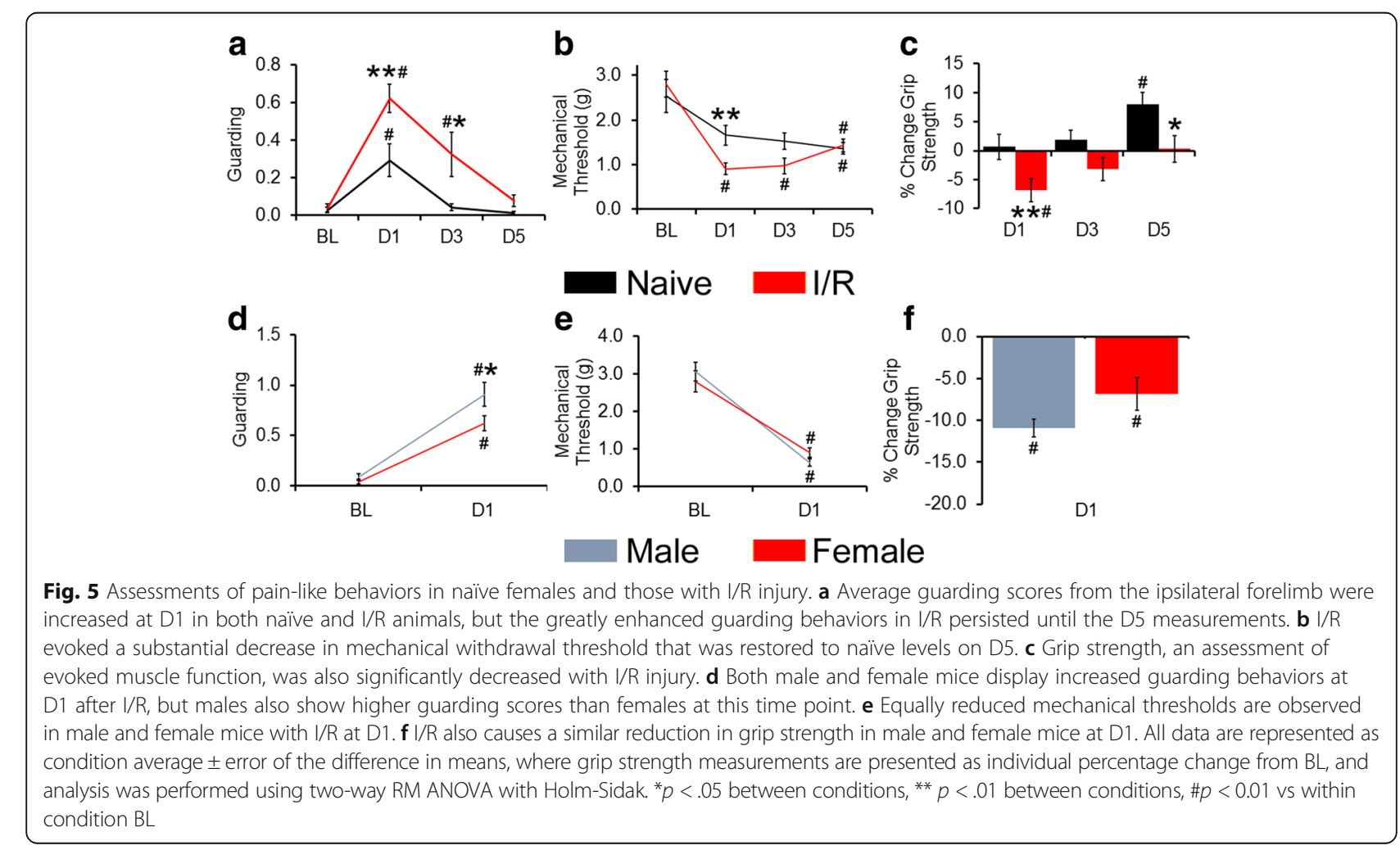


Table 3 Raw behavioral assessment data from females with sham or I/R surgery and uninjured females

\begin{tabular}{|c|c|c|c|c|c|c|c|c|}
\hline \multirow{3}{*}{ Condition } & \multicolumn{8}{|c|}{ Behavioral assessments } \\
\hline & \multicolumn{4}{|c|}{ Guarding score (ipsilateral) } & \multicolumn{4}{|c|}{ Guarding score (contralateral) } \\
\hline & $B L$ & D1 & D3 & D5 & $B L$ & D1 & D3 & D5 \\
\hline Naive & $0.03 \pm 0.02(12)$ & $0.29 \pm 0.09(12)^{\#}$ & $\begin{array}{l}0.04 \pm 0.02 \\
(6)^{* *}\end{array}$ & $0.01 \pm 0.01$ & $0.0 \pm 0.0(12)$ & $0.08 \pm 0.03(12)$ & $\begin{array}{l}0.04 \pm 0.04 \\
(6)^{* *}\end{array}$ & $0.05 \pm 0.05$ \\
\hline Sham & $0.0 \pm 0.0(12)$ & $0.40 \pm 0.09(12)^{\#}$ & $0.23 \pm 0.06(7)$ & $0.05 \pm 0.02(8)$ & $\begin{array}{l}0.01 \pm 0.01 \\
(12)\end{array}$ & $0.11 \pm 0.05(12)$ & $0.21 \pm 0.07(7)$ & $0.02 \pm 0.01$ \\
\hline$I / R$ & $0.04 \pm 0.02(15)$ & $0.62 \pm 0.07(15)^{\# *}$ & $0.32 \pm 0.12(9)^{\#}$ & $0.08 \pm 0.03(11)$ & $\begin{array}{l}0.03 \pm 0.01 \\
(15)\end{array}$ & $\begin{array}{l}0.22 \pm 0.04 \\
(15)^{*}\end{array}$ & $0.23 \pm 0.08(9)^{\#}$ & $\begin{array}{l}0.05 \pm 0.02 \\
(11)\end{array}$ \\
\hline \multirow[t]{2}{*}{ Condition } & \multicolumn{4}{|l|}{ von Frey PWT (g) } & \multicolumn{4}{|c|}{ Grip Strength (g) } \\
\hline & $B L$ & D1 & D3 & D5 & $B L$ & D1 & D3 & D5 \\
\hline Naïve & $2.53 \pm 0.37(12)$ & $\begin{array}{l}1.66 \pm 0.22 \\
(12)^{\# * * *}\end{array}$ & $1.52 \pm 0.18(6)^{\#}$ & $1.37 \pm 0.13(8)^{\#}$ & $78.8 \pm 5.1(12)$ & $79.8 \pm 5.2(12)$ & $87.64 \pm 6.4(6)$ & $96.7 \pm 4.9(8)^{\#}$ \\
\hline Sham & $\begin{array}{l}1.72 \pm 0.24 \\
(12)^{*}\end{array}$ & $0.97 \pm 0.18(12)$ & $1.17 \pm 0.18(7)$ & $1.46 \pm 0.14(8)$ & $86.6 \pm 6.5(12)$ & $80.8 \pm 7.2(12)$ & $87.5 \pm 5.4(7)$ & $95.7 \pm 4.1(8)$ \\
\hline$I / R$ & $2.80 \pm 0.29(15)$ & $0.90 \pm 0.13(15)^{\#}$ & $0.97 \pm 0.18(9)^{\#}$ & $\begin{array}{l}1.44 \pm 0.15 \\
(11)^{\#}\end{array}$ & $88.8 \pm 5.2(15)$ & $78.5 \pm 5.8(15)^{\#}$ & $92.2 \pm 6.1(9)$ & $93.9 \pm 4.3(11)$ \\
\hline
\end{tabular}

Values are presented as mean \pm SEM $(N)$, and analysis was performed using two-way RM ANOVA on condition $x$ time. For ipsilateral forepaw guarding, main effects of time $(p<0.001)$ and injury $(p=0.008)$, and a group x time interaction $(p=0.038)$ were found. For von Frey, a main effect of time $(p<0.001)$ and an interaction was found $(p=0.015)$. For grip strength, a main effect of time was found $(p<0.001)$. Holm-Sidak post hoc analyses indicated ${ }^{*} p<0.05$ vs other conditions, ${ }^{* *} p<0.05$ vs $\mathrm{I} / \mathrm{R},{ }^{\#} p<0.01$ vs within condition BL. PWT: paw withdrawal threshold

mechanically sensitive afferents was significantly greater in females, but unlike previous recordings of nociceptors in vitro [60], no sex difference was detected in the mechanical thresholds of individual muscle afferents. Interestingly, the peak IF to mechanical stimulation was increased in females compared to males, particularly following metabolite stimulation, even though there was no difference in proportion of metabolite-sensitive cells or responsiveness to metabolite solutions. This suggests that metabolite stimulation may potentiate mechanoreceptor responses under basal conditions in females, which has not been previously documented in males [19, 35]. This may be one reason why females display reduced grip strength at baseline compared to males (Fig. 2 ), since grip-induced muscle contractions would produce the metabolites used in ex vivo recordings (e.g., [40]); however, this will need to be confirmed in future studies.

Basal sex differences in nociceptor response properties may originate from altered sensitivity or expression of pain- and sensory-related receptors. While changes in metabolite responsiveness are often linked to DRG upregulation of ASIC3, P2X3, and TRPV1 [40, 41], basal expression of TRPV1 and P2X3 mRNA was found to be significantly lower in females than in males, while ASIC3 did not differ between the sexes (Table 1). The increased firing to heat in females may suggest sex differences in TRPV1 [61, 62], a known heat transducer. However, TRPV1 was also found in this study to undergo I/R-induced upregulation in females (Table 2) without significantly enhancing post-injury heat responses (Fig. 3).
Thus, other modifications in TRPV1 (or other channels not tested) such as enhanced sensitivity or activation may be more likely explanations than increased mRNA expression for female-specific potentiation of muscle afferent heat responses. It is important to note however that gene expression was obtained from whole DRGs and not from muscle afferents specifically.

Additionally, synergistic interactions between P2X3 and TRPV1 have been linked to peripheral afferent sensitization in a variety of models [63-65]. Females experience dynamic changes in DRG P2X3 expression throughout life $[66,67]$ and have unique $\mathrm{P} 2 \mathrm{X} 3$ responses to ATP [68-70]; hence, this channel and its interactions may be particularly relevant in understanding sex effects on muscle afferent responses. Individual muscle afferents are unlikely to respond to ATP alone in culture [40], but ATP action at P2X3 has been long known to potentiate chemical responses in nociceptors [41, 71, 72]. Despite the presence of I/R-induced P2X3 upregulation in both sexes (Table 1), ATP-responsive afferents have not been observed in our previous studies of ischemic injury in males $[19,23,35]$, suggesting that sex-specific contributions of P2X3 in particular may also be relevant to discrete mechanisms of injury-evoked sensitization that necessitate further investigation.

Like previous results from analysis of $I / R$ in males [19, 35], electrophysiological recordings from females exhibited fewer chemosensitive cells responsive to only an innocuous, but not a noxious, metabolite solution (low responders), and decreased mechanical thresholds in individual mechanoreceptors (Fig. 3) 1 day following I/R 
when compared with sex- and age-matched naïves. Although I/R males have consistently displayed more afferents responsive to both metabolite solutions than naïve males, no single response modality was found to be significantly increased following female $I / R$, suggesting that female group III and IV muscle afferent sensitization proceeds through differing, potentially more subtle, mechanisms $[19,35]$.

Additionally, females with I/R also showed substantial increases in firing to thermal stimulation, which correlates with TRPV1 and TRPM8 upregulation within the affected DRGs (Table 1). Males have not been found to experience enhancements of either of these channels following I/R [19, 35]; however, P2X4, another channel linked to cold sensitivity following injury [73], was upregulated in both sexes with 1d I/R [19]. Furthermore, the robust ASIC3 increase induced by IL1 $\beta$ action at IL1r1 in males [35] is absent in females (Table 1), suggesting that sex-dependent alterations in gene expression may underlie differential injury-induced changes in the response properties and phenotypes of individual muscle afferents.

Despite lacking an enhancement in muscle IL1 $\beta$ mRNA, IL1 $\beta$ protein expression in muscles is significantly increased $1 \mathrm{~d}$ following $\mathrm{I} / \mathrm{R}$ in females (Fig. 4). As we found in our previous study of male muscle afferents that IL1 $\beta$ treatment induced TRPV1 upregulation in vitro [35], it is possible that the observed I/R-induced increase in DRG TRPV1 in females may also result from enhanced IL1 $\beta$. Furthermore, effects of IL1 $\beta$ on female sensory afferents may not be limited to changes in gene expression. A previous study by Obreja and colleagues showed that just $1.5 \mathrm{~min}$ exposure to $20 \mathrm{ng} / \mathrm{mL}$ IL1 $\beta$ was sufficient to sensitize cultured female DRG neurons to noxious heat stimulation, likely through activation of PKC [74]. Altogether this suggests that IL1 $\beta$ may modulate I/R-evoked muscle afferent sensitization in females in a variety of ways that may differ from the previous IL1r1-mediated mechanism characterized in males. Further supporting this notion, the IL1 receptor antagonist, which potently inhibits IL1 $\beta / I L 1 r 1$ signaling, was recently found to be ineffective at reducing pain in the treatment of women with chronic fatigue syndrome, which has also been linked to insufficient peripheral perfusion [75]. Regardless, the discrepancy between mRNA and protein expression of IL1 $\beta$ in female muscle following I/R may indicate a slower degradation rate of IL1 $\beta$ protein in females and/or sex differences in the time course of immune infiltration/cytokine upregulation following this type of injury.

Due to the sex- and injury-dependent differences observed within individual muscle afferents, we wanted to confirm that the assays of pain-related behaviors used to describe an ischemic myalgia-like phenotype in male mice with I/R $[19,35]$ would also be appropriate to detect this phenotype in female mice. While individually, these assessments do not directly test muscle specific functions, a combination of these measures along with ex vivo recording provide information about the animals' deep tissue "pain." The overall pattern of $\mathrm{I} / \mathrm{R}$-evoked changes in female pain-related behaviors at D1 was similar to that which had been previously observed in males and confirmed in this report (Fig. 5). Males did, however, display slightly increased guarding at D1 compared to females. Nevertheless, these behaviors, including increased paw guarding, decreased mechanical withdrawal thresholds, and decreased grip strength, were all restored to individual BL or age-matched naïve levels within 5 days after $I / R$ in females [19]. All of these tests have been used because they recapitulate commonly experienced clinical symptoms of ischemic myalgia; however, this approach may have limited the ability to fully correlate physiological and behavioral effects, particularly regarding the altered thermal responses observed both with and without $\mathrm{I} / \mathrm{R}$ in female mice.

Although the experiments performed here were done in a manner similar to our previous work in males, where we had not observed behavioral changes in uninjured animals, both naïve and sham females also experienced enhanced paw guarding. Furthermore, whereas naive and sham males have never been found to differ in any assay performed in our previous I/R studies [19, 35], nor in the electrophysiological data presented here (see Additional file 1), sham females exhibited behavioral characteristics distinct from both naïve and I/R females (Table 3), suggesting a possible female-specific enhancement of incision or surgical pain following sham surgery that is undetectable in males. Because this typically nonnoxious surgery still altered this single pain-related behavior relative to naïves, more investigation will be needed to determine both what may be underlying these changes and if an alternative sham procedure, such as isolating the artery without placing a suture around it for the duration of the injury, may serve as a more inclusive control in studies of both sexes. Interestingly, controlled clinical studies have also documented enhanced post-surgical pain and time to recovery in girls and women as compared to boys and men undergoing similar procedures [33, 76-78]. Altogether, this implies that both naïve and sham controls should be considered for analyses of surgical injury models, particularly in studies of females and/or sex differences.

Recent studies have determined that uninjured rodents, when housed with those who have undergone a painful procedure, may present with similar pain-like behaviors [79-81]. As in our previous work with this injury model, females in this study were socially housed $(\leq 4 /$ cage) with injury conditions mixed within cages to allow 
for adequate blinding; thus, it is possible that the observed increase in guarding behaviors at D1 in naïve and sham females may stem from a similar social transfer. Regardless, this phenomenon was not observed in our previous studies of male mice [19, 35]. Future studies that include females should be performed with this potential cofactor in mind.

\section{Conclusions}

With the comparison of basal contributions of group III and IV primary muscle afferents in age-matched males and females, and characterization of the behavioral, molecular, and physiological correlates of $I / R$ injury in females, this study provides insight into primary sex differences that manifest at the peripheral afferent level. This may not come as a surprise, as sex differences in muscle afferent responses to glutamate have been previously documented in humans and rodents [82]; however, the initial study of the response properties and phenotypes of individual female muscle afferents to natural stimulation at their receptive fields presented here establishes a basic foundation for future research into sex-dependent mechanisms of nociceptive muscle afferent sensitization.

\section{Additional file}

Additional file 1: Comparison of Naïve and Sham male ex vivo response phenotypes. (DOCX $12 \mathrm{~kb}$ )

\section{Acknowledgements}

The authors would like to thank Megan Hoffman and Renita Hudgins for technical support, and Drs. Mark Baccei, Steven Danzer, Jo El Schultz, and Matthew Skelton for helpful comments on this manuscript.

\section{Funding}

This research was supported by grants from the NIH/NIAMS (R01AR064551 to MPJ and F31AR068896 to JLR), the Rita Allen Foundation/American Pain Society (MPJ), and the Department of Anesthesia at CCHMC (MPJ).

\section{Availability of data and materials}

Data generated or analyzed during this study are included in this published article. Full datasets are available from the corresponding author on reasonable request.

\section{Authors' contributions}

$J R$ and MJ designed research. JR, LQ, and MJ performed the electrophysiological recordings and all electrophysiological data was compiled and analyzed for publication by JR. JR and LQ performed tissue excisions from animal subjects. Behavioral and molecular biology assays were performed by $L Q, K G$, JL, and JR, and analyzed by JR, LQ, and MJ. JR wrote the manuscript with the guidance of $\mathrm{MJ}$, and the final version was read and approved by all authors.

\section{Ethics approval}

All experimental procedures were approved by the Cincinnati Children's Hospital Research Foundation Institutional Animal Care and Use Committee and adhered to NIH Standards of Animal Care and Use under Association for Assessment and Accreditation of Laboratory Animal Care Internationalapproved practices.

\section{Consent for publication}

Not applicable.

\section{Competing interests}

The authors declare that they have no competing interests.

\section{Publisher's Note}

Springer Nature remains neutral with regard to jurisdictional claims in published maps and institutional affiliations.

Received: 9 August 2017 Accepted: 20 December 2017

Published online: 03 January 2018

References

1. Gaskin DJ, Richard P. The economic costs of pain in the United States. J Pain. 2012;13(8):715-24.

2. Mense S. The pathogenesis of muscle pain. Curr Pain Headache Rep. 2003; 7(6):419-25.

3. Mense S. Muscle pain: mechanisms and clinical significance. Dtsch Arztebl Int. 2008:105(12):214-9.

4. Clauw DJ. Diagnosing and treating chronic musculoskeletal pain based on the underlying mechanism(s). Best Pract Res Clin Rheumatol. 2015;29(1):6-19.

5. de Mos M, de Bruijn AG, Huygen FJ, Dieleman JP, Stricker BH, Sturkenboom MC. The incidence of complex regional pain syndrome: a population-based study. Pain. 2007;129(1-2):12-20.

6. Muir RL. Peripheral arterial disease: Pathophysiology, risk factors, diagnosis, treatment, and prevention. J Vasc Nurs. 2009;27(2):26-30.

7. Zempsky WT, Palermo TM, Corsi JM, Lewandowski AS, Zhou C, Casella JF. Daily changes in pain, mood and physical function in children hospitalized for sickle cell disease pain. Pain Res Manag. 2013;18(1):33-8.

8. Coderre TJ, Bennett GJ. A hypothesis for the cause of complex regional pain syndrome-type I (reflex sympathetic dystrophy): pain due to deep-tissue microvascular pathology. Pain Med. 2010;11(8):1224-38.

9. Coderre TJ, Xanthos DN, Francis L, Bennett GJ. Chronic post-ischemia pain (CPIP): a novel animal model of complex regional pain syndrome-type I (CRPS-I; reflex sympathetic dystrophy) produced by prolonged hindpaw ischemia and reperfusion in the rat. Pain. 2004;112(1-2):94-105.

10. Wasner G, Schattschneider J, Heckmann K, Maier C, Baron R. Vascular abnormalities in reflex sympathetic dystrophy (CRPS I): mechanisms and disgnostic value. Brain. 2001;124:587-99.

11. Ali FN, Carman TL. Medical management for chronic atherosclerotic peripheral arterial disease. Drugs. 2012;72(16):2073-85.

12. Beard JD. Chronic lower limb ischemia. West J Med. 2000;173(1):60-3.

13. Yang YM, Shah AK, Watson M, Mankad VN. Comparison of costs to the health sector of comprehensive and episodic health care for sickle cell disease patients. Public Health Rep. 1995;110(1):80-6.

14. Aaron LA, Burke MM, Buchwald D. Overlapping conditions among patients with chronic fatigue syndrome, fibromyalgia, and temporomandibular disorder. Arch Int Med. 2000;160(2):221-7.

15. Elvin A, Siosteen AK, Nilsson A, Kosek E. Decreased muscle blood flow in fibromyalgia patients during standardised muscle exercise: a contrast media enhanced colour Doppler study. Eur J Pain. 2006;10(2):137-44.

16. Katz DL, Greene L, Ali A, Faridi Z. The pain of fibromyalgia syndrome is due to muscle hypoperfusion induced by regional vasomotor dysregulation. Med Hypotheses. 2007;69(3):517-25.

17. Blaisdell FW. The pathophysiology of skeletal muscle ischemia and the reperfusion syndrome: a review. Cardiovasc Surg. 2002;10(6):620-30.

18. Liu J, Gao Z, Li J. Femoral artery occlusion increases expression of ASIC3 in dorsal root ganglion neurons. Am J Physiol Heart Circ Physiol. 2010;299(5): H1357-64.

19. Ross $J$, Queme LF, Shank AT, Hudgins RC, Jankowski MP. Sensitization of group III and IV muscle afferents in the mouse after ischemia and reperfusion injury. J Pain. 2014;15(12):1257-70.

20. Xing J, Gao Z, Lu J, Sinoway LI, Li J. Femoral artery occlusion augments TRPV1-mediated sympathetic responsiveness. Am J Physiol Heart Circ Physiol. 2008;295(3):H1262-9.

21. Xing J, Lu J, Li J. Acid-sensing ion channel subtype 3 function and immunolabelling increases in skeletal muscle sensory neurons following femoral artery occlusion. J Physiol. 2012;590(Pt 5):1261-72.

22. Xing J, Lu J, Li J. Contribution of nerve growth factor to augmented TRPV1 responses of muscle sensory neurons by femoral artery occlusion. Am J Physiol Heart Circ Physiol. 2009;296(5):H1380-7.

23. Queme LF, Ross JL, Lu P, Hudgins RC, Jankowski MP. Dual modulation of nociception and cardiovascular reflexes during peripheral ischemia through 
P2Y1 receptor-dependent sensitization of muscle afferents. J Neurosci. 2016; 36(1):19-30.

24. Kaufman MP, Rybicki KJ, Waldrop TG, Ordway GA. Effect of ischemia on responses of group III and IV afferents to contraction. J Appl Physiol Respir Environ Exerc Physiol. 1984;57(3):644-50.

25. Kwon SG, Roh DH, Yoon SY, Moon JY, Choi SR, Choi HS, Kang SY, Han HJ, Beitz AJ, SB O, et al. Acid evoked thermal hyperalgesia involves peripheral P2Y1 receptor mediated TRPV1 phosphorylation in a rodent model of thrombus induced ischemic pain. Mol Pain. 2014;10:2.

26. Seo HS, Roh DH, Yoon SY, Kang SY, Moon JY, Kim HW, Han HJ, Chung JM, Beitz AJ, Lee $\mathrm{JH}$. Peripheral acid-sensing ion channels and $\mathrm{P} 2 \mathrm{X}$ receptors contribute to mechanical allodynia in a rodent thrombus-induced ischemic pain model. J Pain. 2010;11(8):718-27.

27. Gran JT. The epidemiology of chronic generalized musculoskeletal pain. Best Pract Res Clin Rheumatol. 2003;17(4):547-61.

28. Wijnhoven HA, de Vet HC, Picavet HS. Explaining sex differences in chronic musculoskeletal pain in a general population. Pain. 2006;124(1-2):158-66.

29. Wijnhoven HA, de Vet HC, Picavet HS. Prevalence of musculoskeletal disorders is systematically higher in women than in men. Clin J Pain. 2006;22(8):717-24.

30. Greenspan JD, Craft RM, LeResche L, Arendt-Nielsen L, Berkley KJ, Fillingim RB, Gold MS, Holdcroft A, Lautenbacher S, Mayer EA, et al. Studying sex and gender differences in pain and analgesia: a consensus report. Pain. 2007; 132(Suppl 1):S26-45.

31. Allison MA, Ho E, Denenberg JO, Langer RD, Newman AB, Fabsitz RR, Criqui $\mathrm{MH}$. Ethnic-specific prevalence of peripheral arterial disease in the United States. Am J Prev Med. 2007;32(4):328-33.

32. Bingefors $K$, Isacson D. Epidemiology, co-morbidity, and impact on healthrelated quality of life of self-reported headache and musculoskeletal pain-a gender perspective. Eur J Pain. 2004;8(5):435-50.

33. Gommans LN, Scheltinga MR, van Sambeek MR, Maas AH, Bendermacher $B L$, Teijink JA. Gender differences following supervised exercise therapy in patients with intermittent claudication. J Vasc Surg. 2015;62(3):681-8.

34. Baum KF, Dunn DT, Maude GH, Serjeant GR. The painful crisis of homozygous sickle cell disease. A study of the risk factors. Arch Intern Med. 1987;147(7):1231-4

35. Ross JL, Queme LF, Cohen ER, Green KJ, Lu P, Shank AT, An S, Hudgins RC, Jankowski MP. Muscle IL1 beta drives ischemic Myalgia via ASIC3-mediated sensory neuron sensitization. J Neurosci. 2016;36(26):6857-71.

36. Sorge RE, LaCroix-Fralish ML, Tuttle AH, Sotocinal SG, Austin JS, Ritchie J, Chanda ML, Graham AC, Topham L, Beggs S, et al. Spinal cord toll-like receptor 4 mediates inflammatory and neuropathic hypersensitivity in male but not female mice. J Neurosci. 2011;31(43):15450-4

37. Sorge RE, Mapplebeck JCS, Rosen S, Beggs S, Taves S, Alexander JK, Martin L, Austin J-S, Sotocinal SG, Chen D, et al. Different immune cells mediate mechanical pain hypersensitivity in male and female mice. Nat Neurosci. 2015;18(8):1081-3.

38. Doyle HH, Eidson LN, Sinkiewicz DM, Murphy AZ. Sex differences in microglia activity within the Periaqueductal gray of the rat: a potential mechanism driving the dimorphic effects of morphine. J Neurosci. 2017;37(12):3202-14.

39. Posillico CK, Terasaki LS, Bilbo SD, Schwarz JM. Examination of sex and minocycline treatment on acute morphine-induced analgesia and inflammatory gene expression along the pain pathway in Sprague-Dawley rats. Biol Sex Differ. 2015;6(1):33.

40. Light AR, Hughen RW, Zhang J, Rainier J, Liu Z, Lee J. Dorsal root ganglion neurons innervating skeletal muscle respond to physiological combinations of protons, ATP, and lactate mediated by ASIC, P2X, and TRPV1. J Neurophysiol. 2008;100(3):1184-201.

41. Gregory NS, Whitley PE, Sluka KA. Effect of intramuscular protons, lactate, and ATP on muscle hyperalgesia in rats. PLoS One. 2015;10(9):e0138576.

42. Jankowski MP, Rau KK, Ekmann KM, Anderson CE, Koerber HR. Comprehensive phenotyping of group III and IV muscle afferents in mouse. J Neurophysiol. 2013;109(9):2374-81.

43. Ross, Jessica L. Peripheral Mechanisms of Ischemic Myalgia. Electronic Thesis or Dissertation. University of Cincinnati, 2017. Cincinnati: LINK Electronic Theses and Dissertations Center; 2017.

44. Birdsong WT, Fierro L, Williams FG, Spelta V, Naves LA, Knowles M, MarshHaffner J, Adelman JP, Almers W, Elde RP, et al. Sensing muscle ischemia: coincident detection of acid and ATP via interplay of two ion channels. Neuron. 2010;68(4):739-49.

45. Pan HL, Longhurst JC, Eisenach JC, Chen SR. Role of protons in activation of cardiac sympathetic C-fibre afferents during ischaemia in cats. J Physiol. 1999;518(Pt 3):857-66
46. Bangsbo J, Aagaard T, Olsen M, Kiens B, Turcotte LP, Richter EA. Lactate and $\mathrm{H}+$ uptake in inactive muscles during intense exercise in man. J Physiol. 1995:488(Pt 1):219-29.

47. Bangsbo J, Johansen L, Graham T, Saltin B. Lactate and H+ effluxes from human skeletal muscles during intense, dynamic exercise. J Physiol. 1993; 462:115-33.

48. Li J, King NC, Sinoway LI. Interstitial ATP and norepinephrine concentrations in active muscle. Circulation. 2005;111(21):2748-51.

49. Li J, King NC, Sinoway LI. ATP concentrations and muscle tension increase linearly with muscle contraction. J Appl Physiol (1985). 2003;95(2):577-83.

50. Lánský $P$, Rodriguez $R$, Sacerdote L. Mean instantaneous firing frequency is always higher than the firing rate. Neural Comput. 2004;16(3):477-89.

51. Jankowski MP, Ross JL, Weber JD, Lee FB, Shank AT, Hudgins RC. Agedependent sensitization of cutaneous nociceptors during developmental inflammation. Mol Pain. 2014:10:34.

52. Elitt CM, Mcllwrath SL, Lawson JJ, Malin SA, Molliver DC, Cornuet PK, Koerber HR, Davis BM, Albers KM. Artemin overexpression in skin enhances expression of TRPV1 and TRPA1 in cutaneous sensory neurons and leads to behavioral sensitivity to heat and cold. J Neurosci. 2006;26(33):8578-87.

53. Jankowski MP, Lawson JJ, Mcllwrath SL, Rau KK, Anderson CE, Albers KM, Koerber HR. Sensitization of cutaneous nociceptors after nerve transection and regeneration: possible role of target-derived neurotrophic factor signaling. J Neurosci. 2009;29(6):1636-47.

54. Liu X, Green KJ, Ford ZK, Queme LF, Lu P, Ross JL, Lee FB, Shank AT, Hudgins RC, Jankowski MP. Growth hormone regulates the sensitization of developing peripheral nociceptors during cutaneous inflammation. Pain. 2017;158(2):333-46.

55. Xu J, Brennan TJ. Guarding pain and spontaneous activity of Nociceptors after skin versus skin plus deep tissue incision. Anesthesiol. 2010;112:155-64.

56. Bartley EJ, Fillingim RB. Sex differences in pain: a brief review of clinical and experimental findings. Br J Anaesth. 2013;111(1):52-8.

57. Fillingim RB, Gear RW. Sex differences in opioid analgesia: clinical and experimental findings. Eur J Pain. 2004;8(5):413-25.

58. Riley JL 3rd, Robinson ME, Wise EA, Myers CD, Fillingim RB. Sex differences in the perception of noxious experimental stimuli: a meta-analysis. Pain. 1998;74(2-3):181-7.

59. Gregory NS, Gibson-Corley K, Frey-Law L, Sluka KA. Fatigue-enhanced hyperalgesia in response to muscle insult: induction and development occur in a sex-dependent manner. Pain. 2013;154(12):2668-76.

60. Hendrich J, Alvarez $P$, Joseph EK, Ferrari LF, Chen $X$, Levine JD. In vivo and in vitro comparison of female and male nociceptors. J Pain. 2012; 13(12):1224-31.

61. Caterina MJ, Leffler A, Malmberg AB, Martin WJ, Trafton J, Petersen-Zeitz KR, Koltzenburg M, Basbaum Al, Julius D. Impaired nociception and pain sensation in mice lacking the capsaicin receptor. Science. 2000; 288(5464):306-13.

62. Dhaka A, Viswanath V, Patapoutian A. Trp ion channels and temperature sensation. Annu Rev Neurosci. 2006;29:135-61.

63. Kiyatkin ME, Feng B, Schwartz ES, Gebhart GF. Combined genetic and pharmacological inhibition of TRPV1 and P2X3 attenuates colorectal hypersensitivity and afferent sensitization. Am J Physiol Gastrointest Liver Physiol. 2013;305(9):G638-48

64. Saloman JL, Chung MK, Ro JY. P2X(3) and TRPV1 functionally interact and mediate sensitization of trigeminal sensory neurons. Neuroscience. 2013; 232:226-38.

65. Shieh KR, Yang SC, Tseng HL, Yi CH, Liu TT, Chen CL. Evidence for upregulation of purinergic receptor genes associating with TRPV1 receptors and neurotrophic factors in the inflamed human esophagus. Curr Mol Med. 2014;14(9):1205-14.

66. Ma B, Yu LH, Fan J, Cong B, He P, Ni X, Burnstock G. Estrogen modulation of peripheral pain signal transduction: involvement of $\mathrm{P} 2 \mathrm{X}(3)$ receptors. Purinergic Signal. 2011;7(1):73-83.

67. Papka RE, Hafemeister J, Storey-Workley M. P2X receptors in the rat uterine cervix, lumbosacral dorsal root ganglia, and spinal cord during pregnancy. Cell Tissue Res. 2005;321(1):35-44.

68. Schmitt PM, Gohil K, Kaufman MP. Spinal estrogen attenuates the exercise pressor reflex but has little effect on the expression of genes regulating neurotransmitters in the dorsal root ganglia. J Appl Physiol (1985). 2006; 100(3):958-64

69. Schmitt PM, Kaufman MP. Estrogen attenuates the exercise pressor reflex in female cats. J Appl Physiol (1985). 2003;95(4):1418-24. 
70. Cho T, Chaban W. Interaction between P2X3 and oestrogen receptor (ER)alpha/ERbeta in ATP-mediated calcium signalling in mice sensory neurones. J Neuroendocrinol. 2012;24(5):789-97.

71. Ellrich J, Makowska A. Nerve growth factor and ATP excite different neck muscle nociceptors in anaesthetized mice. Cephalalgia. 2007;27(11):1226-35.

72. Petruska JC, Napaporn J, Johnson RD, Gu JG, Cooper BY. Subclassified acutely dissociated cells of rat DRG: histochemistry and patterns of capsaicin-, proton-, and ATP-activated currents. J Neurophysiol. 2000;84(5):2365-79.

73. Jurga AM, Piotrowska A, Makuch W, Przewlocka B, Mika J. Blockade of P2X4 receptors inhibits neuropathic pain-related behavior by preventing MMP-9 activation and, consequently, Pronociceptive interleukin release in a rat model. Front Pharmacol. 2017;8:48.

74. Obreja O, Rathee PK, Lips KS, Distler C, Kress M. IL-1 beta potentiates heatactivated currents in rat sensory neurons: involvement of IL-1RI, tyrosine kinase, and protein kinase C. FASEB J. 2002:16(12):1497-503.

75. Roerink ME, Bredie SJ, Heijnen M, Dinarello CA, Knoop H, Van der Meer JW. Cytokine inhibition in patients with chronic fatigue syndrome: a randomized trial. Ann Intern Med. 2017;166:557-64.

76. Bell MR, Garratt KN, Bresnahan JF, Holmes DR Jr. Immediate and long-term outcome after directional coronary atherectomy: analysis of gender differences. Mayo Clin Proc. 1994;69(8):723-9.

77. Kalkman CJ, Visser K, Moen J, Bonsel GJ, Grobbee DE, Moons KG. Preoperative prediction of severe postoperative pain. Pain. 2003;105(3):415-23.

78. Sadhasivam S, Chidambaran V, Olbrecht VA, Costandi A, Clay S, Prows CA, Zhang $X$, Martin LJ. Opioid-related adverse effects in children undergoing surgery: unequal burden on younger girls with higher doses of opioids. Pain Med. 2015;16(5):985-97.

79. Smith ML, Hostetler CM, Heinricher MM, Ryabinin AE. Social transfer of pain in mice. Sci Adv. 2016;2(10):e1600855.

80. Li Z, Lu YF, Li CL, Wang Y, Sun W, He T, Chen XF, Wang XL, Chen J. Social interaction with a cagemate in pain facilitates subsequent spinal nociception via activation of the medial prefrontal cortex in rats. Pain. 2014; 155(7):1253-61.

81. Langford DJ, Crager SE, Shehzad Z, Smith SB, Sotocinal SG, Levenstadt JS, Chanda ML, Levitin DJ, Mogil JS. Social modulation of pain as evidence for empathy in mice. Science. 2006;312(5782):1967-70.

82. Cairns BE, Hu JW, Arendt-Nielsen L, Sessle BJ, Svensson P. Sex-related differences in human pain and rat afferent discharge evoked by injection of glutamate into the masseter muscle. J Neurophysiol. 2001;86(2):782-91.

\section{Submit your next manuscript to BioMed Central and we will help you at every step:}

- We accept pre-submission inquiries

- Our selector tool helps you to find the most relevant journal

- We provide round the clock customer support

- Convenient online submission

- Thorough peer review

- Inclusion in PubMed and all major indexing services

- Maximum visibility for your research

Submit your manuscript at www.biomedcentral.com/submit

) Biomed Central 